\title{
Are protected areas maintaining bird diversity?
}

\author{
Laura Rayner, David B. Lindenmayer, Jeffrey T. Wood, Philip Gibbons and Adrian D. Manning
}

L. Rayner(laura.rayner@anu.edu.au), D. B. Lindenmayer,J. T. Wood, P. Gibbons and A. D. Manning, Fenner School of Environment and Society, The Australian National Univ., Canberra, ACT 0200, Australia. DBL and PG also at: ARC Centre of Excellence for Environmental Decisions, National Environmental Research Program, The Australian National Univ., Canberra, ACT 0200, Australia.

\begin{abstract}
Evaluating the effectiveness of protected areas for sustaining biodiversity is crucial to achieving conservation outcomes. While studies of effectiveness have improved our understanding of protected-area design and management, few investigations $(<5 \%)$ have quantified the ecological performance of reserves for conserving species. Here, we present an empirical evaluation of protected-area effectiveness using long-term measures of a vulnerable assemblage of species. We compare forest and woodland bird diversity in the Australian Capital Territory over 11 yr on protected and unprotected areas located in temperate eucalypt woodland and matched by key habitat attributes. We examine separately the response of birds to protected areas established prior to 1995 and after 1995 when fundamental changes were made to regional conservation policy. Bird diversity was measured in richness, occurrence of vulnerable species, individual species trajectories and functional trait groups. We found that protected areas were effective in maintaining woody vegetation cover in the study region, but were less effective in the protection of the target bird species assemblage. Protected areas were less species rich than unprotected areas, with significant declines in richness across sites protected prior to 1995 . Small, specialised and vulnerable species showed stronger associations with unprotected areas than protected areas. Our findings indicate that recently established reserves (post-1995) are performing similarly to unprotected woodland areas in terms of maintaining woodland bird diversity, and that both of these areas are more effective in the conservation of woodland bird populations than reserves established prior to 1995 . We demonstrate that the conservation value of protected areas is strongly influenced by the physical characteristics, as well as the landscape context, of a given reserve and can diminish with changes in surrounding land use over time. Both protected areas and off-reserve conservation schemes have important roles to play in securing species populations.
\end{abstract}

Conserving biodiversity through protected areas has been at the core of global conservation strategies for more than a century (Pimm et al. 2001). Today, over 160000 protected areas covering between 10.8 and $12.7 \%$ of the Earth's terrestrial surface comprise the global protected-area network (Bertzky et al. 2012, WDPA 2012). The primary objective of a protected area is 'to achieve the long-term conservation of nature with associated ecosystem services', where 'conservation' refers to 'the in-situ maintenance of ecosystems... and of viable populations of species in their natural surroundings' (Dudley 2008, pp. 8-9). Protected areas draw heavily on limited conservation resources in striving to achieve this objective (Brooks et al. 2004). Yet, the world continues to experience unprecedented levels of biodiversity loss (WWF 2012) and ongoing destruction of natural habitat (FAO 2011), sometimes within areas designated for biodiversity protection (DeFries et al. 2005).

Consequently, the capacity for protected areas to protect and maintain biological diversity is contested (Joppa et al. 2008), bringing their effectiveness as a global conservation tool into question. It is therefore essential to measure protected-area effectiveness as the first step towards improving biodiversity management efforts, and rectifying failures to achieve conservation goals.

To assess the effectiveness of protected areas, studies predominantly focus on one of three subjects: design, management processes, or ecological integrity (sensu Ervin 2003). We reviewed the empirical literature on protectedarea effectiveness (539 studies) and found that studies of design, management and ecological integrity accounted for 39, 44 and $17 \%$ of articles respectively (Rayner unpubl.). Importantly, only a small subset of studies $(<5 \%)$ directly quantified the effectiveness of protection for sustaining biodiversity. This finding supports calls from the scientific community for greater research focus on the ecological effectiveness of protected areas to provide direct measures of conservation outcomes and enhance adaptive decision making (Gaston et al. 2008, Jones et al. 2011).

Here, we define 'ecological effectiveness' as the ongoing maintenance or recovery of biodiversity within areas implicitly or explicitly established for its protection. A comprehensive assessment of ecological effectiveness requires, at the least, comparative and temporal data. That is, the status of biodiversity in the presence and absence of protection should 
be compared through time. This is critical for determining whether ecosystems are showing direct and sustained benefits from protection. This approach is distinct from most available studies on protected-area design (e.g. location, coverage), management (e.g. funding, enforcement) and integrity (e.g. intactness, threats), which often evaluate effectiveness using proximal measures that are assumed to be reliable surrogates of biodiversity conservation, but are rarely tested (Brooks et al. 2004).

Important studies of ecological effectiveness exist, but few have measured the impact of protection on species populations; a core biodiversity indicator (Brooks et al. 2004, Gaston et al. 2006). For example, several studies examine the response of vegetative cover to protection over time using retrospectively collected, remotely-sensed, timeseries data (Mas 2005, Andam et al. 2008). However, such methods cannot be used to track species populations, which rely on field-based monitoring records that are often difficult to obtain (Lindenmayer and Likens 2010). Consequently, studies that utilise long-term monitoring records to assess protected-area effectiveness are scarce (Gaston et al. 2006). As a result, the capacity for protected areas to ensure the persistence of species populations is poorly understood, and this has been identified as a significant knowledge gap in protected-area research (Gaston et al. 2008).

In this paper, we studied ecological effectiveness using a dataset for forest and woodland birds observed in temperate eucalypt woodland within and without protected areas spanning $11 \mathrm{yr}$. We pose four primary questions: 1) do protected areas support higher bird species richness than unprotected areas over time? 2) Do protected areas support more birds of conservation concern than unprotected areas over time? 3) Do protected areas support more species with stable or increasing trends than unprotected areas? 4) Do protected areas benefit birds with particular functional traits?

Where possible, we assessed separately, the response of birds to protected areas that were established pre- and post-1995, following a change in legislation that reprioritised reserve selection criteria in the study region. This allowed us to account for developments in global reserve-selection standards. Further, to characterise protected-area conditions and explore potential environmental predictors of species-site occurrence, we investigated the physical characteristics (area and elevation), landscape context (relative topographic position and urban proximity) and environmental processes (woody vegetation cover and plant productivity) associated with our study sites. In doing so, our study demonstrates the strength of long-term ecological monitoring in evaluations of protected-area performance.

\section{Material and methods}

\section{Study region and protected areas}

Eucalypt woodland once covered over 1.5 million $\mathrm{km}^{2}$ of the Australian continent (NLWRA 2001), this is the equivalent to the area of $19 \%$ of the lower 48 states of the USA. Since European settlement, almost 28\% has been cleared, and less than $8 \%$ of the remainder is protected (NLWRA
2001). Consequently, these woodlands are an internationallyrecognised endangered ecoregion (Hoekstra et al. 2005). We used a $20 \times 40 \mathrm{~km}$ area in the north-east region of the Australian Capital Territory (ACT) in south-eastern Australia (Fig. 1a) as an exemplar of this highly-modified, continent-scale ecosystem type. Prior to European settlement in 1824 , this region was dominated by temperate eucalypt woodland (or temperate broad-leaf/mixed forest, sensu Jenkins and Joppa 2009). The type of temperate woodland found in this area (box-gum grassy woodland) is listed as critically endangered at the national level (ACT 2011). However, woodland remnants of the ACT are typically larger, more intact, and more adequately protected than woodlands found anywhere else in Australia (ACT 2004). These remnants make a significant contribution to the global protection of this biome (Jenkins and Joppa 2009).

For this study, sites in protected areas were located within the Canberra Nature Park, a series of protected areas within a matrix of urban and rural land uses (Fig. 1b). These protected areas contain the highest quality longitudinal records of birds and provide the best representation of protected temperate woodland for the region, including one woodland sanctuary ( $<$ www.mfgowoodlandexperiment.org. $\mathrm{au}>$ ) and large areas of Eucalyptus melliodoralEucalyptus blakelyi Grassy Woodland, an endangered ecological community in the ACT (ACT 2011).

\section{Bird surveys and site selection}

We sourced records of bird occurrence from a long-term woodland bird monitoring project undertaken by the Canberra Ornithologists Group (COG). The design and execution of this project was based on statistical principles ensuring a sound data collection framework (see Bounds et al. 2010 for further information). From this database, we selected 92 study sites nested within 10 broad locations for analysis (Fig. 1c). Sites were circular plots of $50 \mathrm{~m}$ radius. All sites were surveyed over an 11-yr period between 2000 and 2010. Where possible, bird surveys were conducted seasonally, providing four surveys per year for each site. However, some variation in survey effort occurred in the dataset. Bird surveys were $10 \mathrm{~min}$ point counts recording all bird species seen or heard within a $50 \mathrm{~m}$ radius of a permanent marker point (Bounds et al. 2010).

To compare bird responses, we located sites on both protected and unprotected land (hereafter 'reserved sites' and 'unreserved sites'). All reserved sites were managed strictly for biodiversity protection under IUCN protection class I-IV. Unreserved sites were of mixed land tenures and varied in the level of active biodiversity management, from very little (e.g. grazed leasehold land) to substantial (e.g. meeting statutory obligations on defence land). Reserved and unreserved sites were matched in three key characteristics: 1) all sites occurred in either temperate grassy woodland (86 sites) or dry forest contiguous with temperate grassy woodland (six sites), 2) all sites were dominated by eucalypt tree species with Eucalyptus blakelyi, Eucalyptus melliodora, Eucalyptus bridgesiana, Eucalyptus macroryncha and Eucalyptus polyanthemos being the most common overstorey trees, and 3) all sites were located within $25 \mathrm{~km}$ of the 

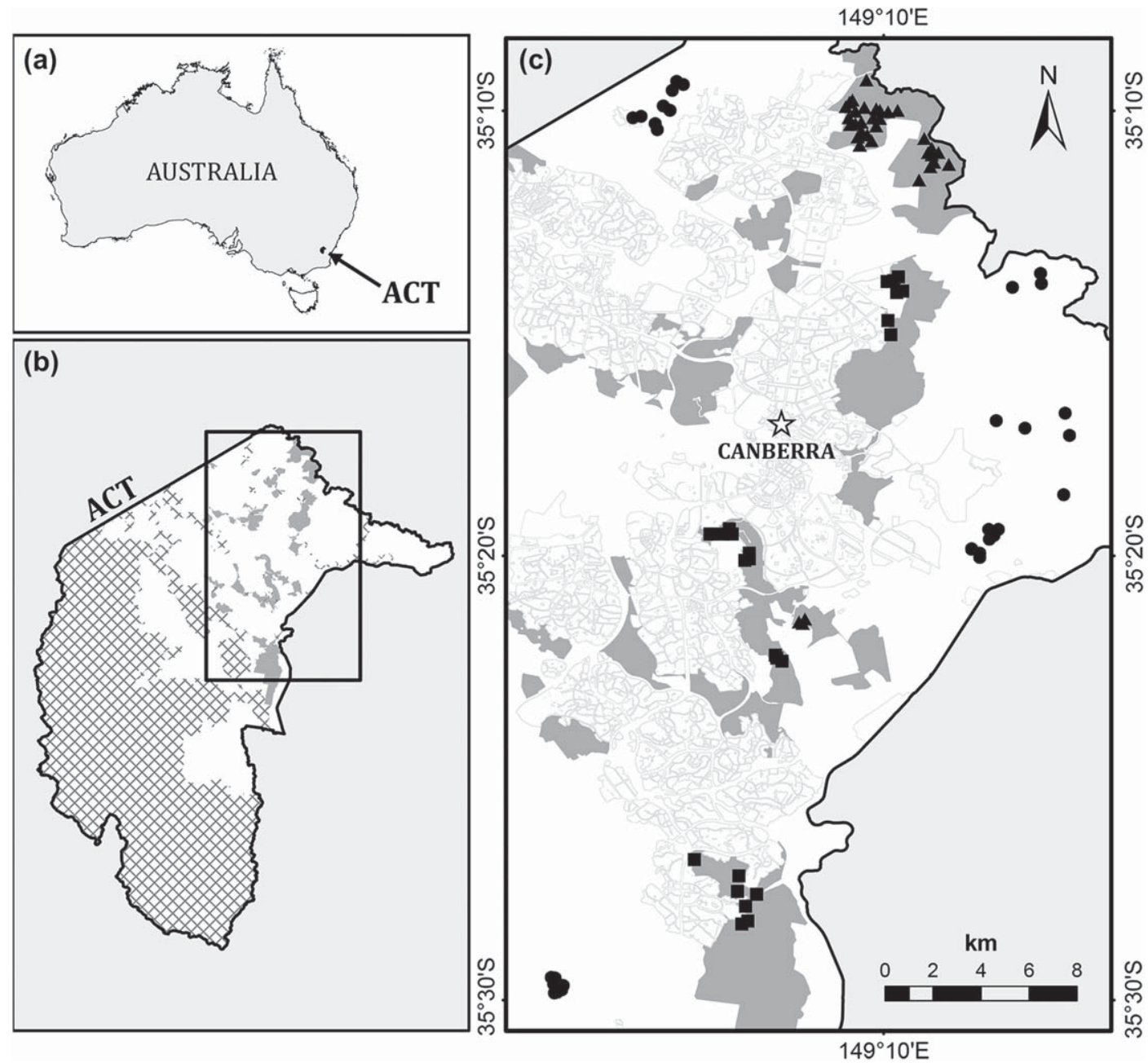

Figure 1. Map of study area. (a) Position of the Australian Capital Territory (ACT) within Australia. (b) Distribution of protected areas within the ACT, showing Canberra Nature Parks (shaded grey) and all other protected areas (cross-hatched). (c) Location of sites in pre-1995 reserves (squares), post-1995 reserves (triangles) and unreserved land (circles). Distribution of Canberra Nature Parks (shaded grey) and urban development (grey lines) within the study region. Location of Canberra, the capital city, is denoted by a star.

city of Canberra and were likely to have been subject to some level of modification over time as a result of fire, grazing and/or invasion from weeds and feral species. More remote woodland sites were not available due to limited habitat protection and a paucity of longitudinal bird data.

\section{Reservation categories}

The number of reserved and unreserved sites changed over time as 12 sites gained reservation status during the survey period (Table 1). This meant that, in any given year, data for 'reserved sites' included surveys from sites added recently to the reserve system where, one could argue, the effects of legal protection may not have had time to manifest. Despite this caveat, we argue that recently reserved sites make an important contribution to this study. Theoretically, the addition of reserved sites in a study where the total number of sites is fixed, should favour the long-term conservation performance of reserves if representativeness is the guiding principle behind land acquisition.
Within our sample of reserved sites, we examined separately, the response of birds to reserves established prior to 1995 and reserves established since 1995. The year 1995 coincides with a period of change in the motivation behind reserve establishment in the ACT, shifting reserve objectives

Table 1. Reservation status of sites. The number of sites represented by the three reservation categories (pre-1995 reserved sites, post1995 reserved sites and unreserved sites) and their corresponding years of gazettal. Note that the total number of sites is fixed $(n=92)$. Twelve sites gained reservation status during the survey period (2000-2010). The total for unreserved sites is the number of sites that were unprotected for the duration of the survey period.

\begin{tabular}{lccc}
\hline $\begin{array}{l}\text { Year of } \\
\text { establishment }\end{array}$ & $\begin{array}{c}\text { Pre-1995 } \\
\text { reserved sites }\end{array}$ & $\begin{array}{c}\text { Post-1995 } \\
\text { reserved sites }\end{array}$ & $\begin{array}{c}\text { Unreserved } \\
\text { sites }\end{array}$ \\
\hline 1975 & 14 & 0 & 78 \\
1987 & 10 & 0 & 68 \\
1995 & 0 & 22 & 46 \\
2003 & 0 & 9 & 37 \\
2004 & 0 & 3 & 34 \\
Total & 24 & 34 & 34 \\
\hline
\end{tabular}


from those of scenic value to conservation value (ACT 1994). Consequently, this provides a unique opportunity to examine the effect of changed global standards in reserve selection. Thus, three reservation categories were created for analysis: pre-1995 reserved sites $(\mathrm{n}=24)$, post-1995 reserved sites $(\mathrm{n}=34)$, and unreserved sites $(\mathrm{n}=34)($ Table 1$)$.

\section{Species of conservation concern}

We assigned conservation status to each bird species based on regionally-relevant current literature. Here, species of conservation concern included species that were declared as vulnerable at a regional level (ACTFFC 2011) or have exhibited a long-term declining trend in the region over the last decade (Bounds et al. 2010). We present the conservation status of each species in Supplementary material Appendix 1, Table A1.

\section{Species traits}

Many authors encourage the use of functional trait analysis in ecological studies for a deeper understanding of community responses to environmental conditions (Devictor and Robert 2009). This is particularly relevant where changes to community composition might be missed by simple diversity measures such as richness (Filippi-Codaccioni et al. 2010). We therefore assigned each species to functional trait groups based on life-history attributes. These groups included habitat specialisation (woodland dependent, non-woodland dependent), bird mobility (resident and sedentary species versus migratory, part-migratory and dispersive species), body weight, nest type (e.g. hollow, cup, dome), nest location (e.g. arboreal, understorey, ground), main food type (e.g. invertebrates, seed, nectar), foraging substrate (e.g. aerial, arboreal, shrub) and whether the species feeds on the ground. A species could belong to multiple functional trait groups. We provide details of trait assignment for individual species and reference material in Supplementary material Appendix 1, Table A1.

\section{Environmental descriptors}

We examined four broad-scale environmental variables for their relationship with area protection and species functional traits. These were: woody vegetation cover, potential productivity, plant productivity, and proximity to the urban boundary. We chose these variables for two primary reasons: 1) their documented influence on woodland bird communities (Chace and Walsh 2006, Huth and Possingham 2011, Montague-Drake et al. 2011); and 2) their strength and increasing availability as data types to be used in protectedarea design, management and performance assessments (Mas 2005, Radeloff et al. 2010). We also compared these variables, as well as reserve area, elevation and landscape position, across reservation categories. In doing so, we examined: 1) differences in physical reserve characteristics as an indicator of biases in reserve establishment, and 2) changes in ecological processes as an indicator of disturbance. We provide details on source and method of data collection for each environmental descriptor in Supplementary material Appendix 2, Table A2.

\section{Data structure and statistical analyses}

In total, we used 3768 bird surveys over $11 \mathrm{yr}$ in our analysis. Bird surveys were not available for one unreserved location, Majura Training Area (8 sites), between 2001 and 2003. All other sites were surveyed in all years. The spatio-temporal structure of the dataset is presented in Supplementary material Appendix 3, Fig. A3.

For our analyses, we examined all species detected in $>1 \%$ of surveys, excluding waterbirds $(n=60)$. These species are listed in Supplementary material Appendix 1, Table A1. We pooled bird surveys annually to give three measures per site: 1) richness, the total number of species detected; 2) proportion, the number of surveys in which a species was detected as a proportion of the total number of surveys conducted in that year; and 3) presence, the species detected in at least one of the surveys conducted for each year. We derived all of these measures from presence/absence data. For all analyses, $\chi^{2}$ test statistics quoted are derived for Wald statistics.

\section{Trends in richness and species occurrence}

We fitted hierarchical generalised linear models (HGLM, Lee et al. 2006) to determine whether bird responses differed across reservation categories over time. To do so, we calculated longitudinal trend patterns for: 1) species richness, 2) species of conservation concern, and 3) each species separately. The first two analyses assumed a Poisson distribution and we used the richness measure as the response, with survey effort included as a fixed effect. For individual species, we fitted quasi-binomial models with the proportion measure as the response, accounting for variability in survey effort directly. For both models, we included location and site as random effects to account for the influence of spatial autocorrelation that could result from the clustering of sites within locations. For 11 of the rarer species, there were insufficient data to estimate separate location and site components of variance. In these cases, we estimated the pooled variance of location and site combined. We fitted the HGLMs in GenStat statistical software package (14th ed.).

\section{Functional trait analysis}

We used RLQ analysis (Doledec et al. 1996) to relate environmental conditions and species functional traits to patterns in species-site occurrence (using the presence measure). RLQ analysis explains variation in species composition using scores derived from the ordinations of three separate matrices: (R) site by environmental descriptors, (L) site by species, and $(\mathrm{Q})$ species by functional traits. We used reservation status as an environmental descriptor in the $\mathrm{R}$ matrix, to highlight the environmental conditions and species traits that are most strongly associated with reserved and unreserved sites.

A challenge with RLQ analysis is dealing with both spatial and temporal autocorrelation within the dataset. Including location and year as descriptors in the ordinations would mask the contribution of our environmental 
conditions of interest because: 1) location remains unchanged through time, and 2) surveys within years are likely to be more similar due to abiotic factors. RLQ analysis does not account for such random effects. To overcome this issue, we performed two separate analyses: one using data collected in 2000 and the second on data collected in 2010. This approach allowed us to maximise the covariance between site and species scores using only the environmental descriptors directly relevant to our aims. Furthermore, this approach allowed us to compare the relative influence of explanatory variables across two points in time (by standardising the RLQ eigenvectors for each year), while minimising the variance explained by location that would be inflated by pooling all survey years together. As we used only two years in this analysis (2000 and 2010), reservation categories were constrained to 'reserved' versus 'unreserved' categories.

We assessed the statistical strength of the analysis using a permutation test (1000 permutations) and by comparing variance explained by the RLQ analysis to separate R, L and $\mathrm{Q}$ ordinations. We conducted RLQ analysis in the R statistical program (R Development Core Team), using the ade4 software package.

\section{Environmental differences among reservation categories}

We used HGLMs to examine differences in environmental descriptors across reservation categories. We compared static environmental descriptors across reserves using analysis of variance (ANOVA) with location as a blocking variable. We calculated all static environmental descriptors as means at the reserve-level. Where environmental descriptors were derived from time-series data (temporal environmental descriptors), we used HGLMs to compare variation across reservation categories through time. These models included location as a random effect. We calculated all temporal environmental descriptors at the site-level. We performed both ANOVA and HGLMs in GenStat statistical software package (14th ed.).

\section{Results}

\section{Species richness}

We found a significant difference in species richness between reservation groups $\left(\chi_{3}^{2}=596, \mathrm{p}<0.001\right)$ with unreserved sites supporting higher mean species richness for most years (Fig. 2). There also was a strong interaction between reservation category and time $\left(\chi_{3}^{2}=76, \mathrm{p}<0.001\right)$ with a decline in richness on pre-1995 reserved sites and an increase in richness on unreserved sites (Fig. 2). While these trends were highly significant, differences in expected (mean) richness among reservation categories were small for most years (Supplementary material Appendix 4, Table A4). There was no significant change in species richness on post1995 reserved sites during the survey period (Fig. 2).

\section{Number of species of conservation concern}

The number of species of conservation concern was consistently lower on reserved sites, regardless of year or reservation

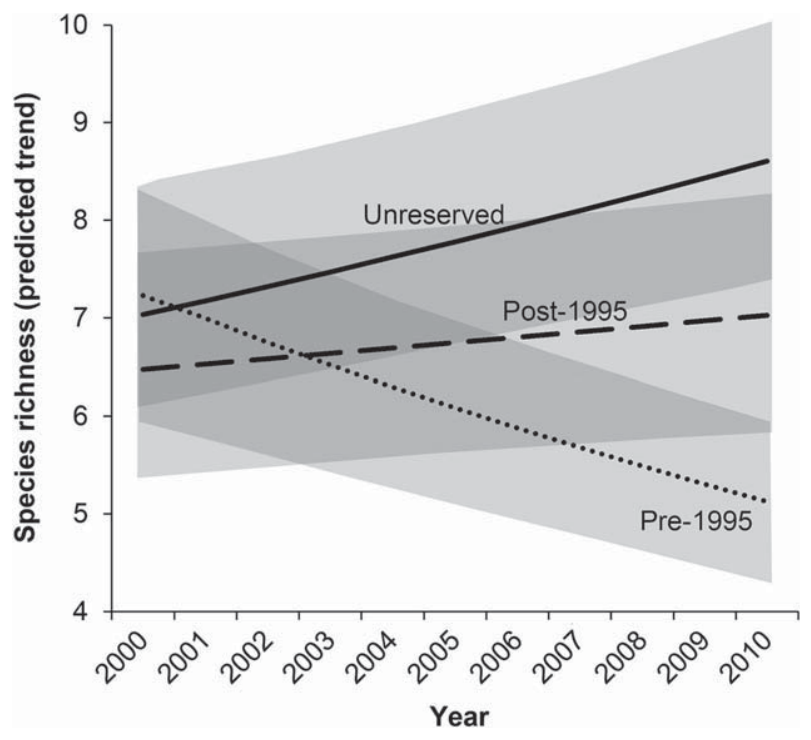

Figure 2. Results of HGLM showing changes in mean species richness over time on sites reserved pre-1995, sites reserved post-1995 and unreserved sites. Standard errors for the model predictions, which include the random effect of location, are shown in grey.

category $\left(\chi_{3}^{2}=32, \mathrm{p}<0.001\right)$ (Fig. 3). Like total species richness, there was a significant interaction between reserve category and time $\left(\chi_{3}^{2}=64, \mathrm{p}<0.001\right)$, driven by a decline in the number of species of concern on pre1995 reserved sites (Fig. 3). In contrast, the number of species of conservation concern remained stable on post-1995 reserved sites and unreserved sites during the survey period (Fig. 3, Supplementary material Appendix 4, Table A4).

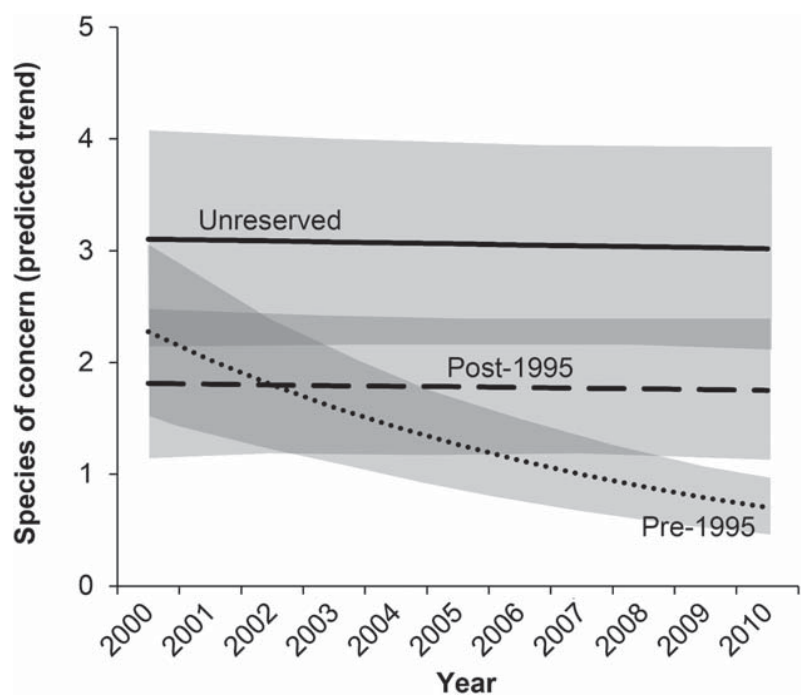

Figure 3. Results of HGLM showing changes in mean richness of bird species of conservation concern over time on sites reserved pre1995, sites reserved post-1995 and unreserved sites. Standard errors for the model predictions, which include the random effect of location, are shown in grey. 


\section{Longitudinal trends}

Of the 60 species detected in $>1 \%$ of surveys, 35 showed significant temporal trends in response to our reservation categories (Table 2, Supplementary material Appendix 4, Table A4). Temporal trends for a further six species were strong, but not significant $(\mathrm{p}=0.05-0.1)$, leaving 18 species exhibiting no significant change in detection over time, for any reservation category. An examination of the longterm trends of individual species and their responses to reservation categories revealed three types of patterns: 1) increasers, species for which a significant temporal trend was always positive, 2) decliners, species for which a significant temporal trend was always negative, and 3) species that showed contrasting temporal trends dependent on reservation category (Table 2 ).

1) Increasers. Twelve species were identified as increasers in this study (Table 2). Of these, four showed significant increasing trends across all reservation categories. These species were Australian king-parrot Alisterus scapularis, Australian raven Corvus coronoides, crested pigeon Ocyphaps lophotes, and noisy miner Manorina melanocephala. Of the 12 increasers, only three were defined as woodlanddependent: Australian king-parrot, sacred kingfisher Todiramphus sanctus and the white-eared honeyeater

Table 2. Results of HGLM showing individual species trends (Slope) including standard errors (SE) on pre- and post-1995 reserved sites, and unreserved sites. Only species with strong or significant trends $(\mathrm{p}<0.1)$ are presented $(\mathrm{n}=42)$. Significance is indicated by the Wald statistic $\left(\chi_{d f}^{2}\right)$ and $p$-value as follows: $* p<0.05, * * p<0.01, * * * p<0.001$. Strong trends $(p=0.05-0.10)$ are presented in italics. Non-significant trends for individual reservation categories are presented in grey. Species are listed in order of detection frequency. Scientific names for species are provided in Supplementary material Appendix 1, Table A1.

\begin{tabular}{|c|c|c|c|c|c|c|c|c|}
\hline \multirow[b]{2}{*}{ Common name } & \multirow[b]{2}{*}{$\begin{array}{c}\text { Surveys } \\
\text { present }(\%)\end{array}$} & \multirow{2}{*}{$\begin{array}{c}\begin{array}{c}\text { Reservation } \times \\
\text { year }\end{array} \\
\chi_{3}^{2}\end{array}$} & \multicolumn{2}{|c|}{$\begin{array}{l}\text { Pre-1995 } \\
\text { reserved trend }\end{array}$} & \multicolumn{2}{|c|}{$\begin{array}{l}\text { Post-1995 } \\
\text { reserved trend }\end{array}$} & \multicolumn{2}{|c|}{$\begin{array}{l}\text { Unreserved } \\
\text { trend }\end{array}$} \\
\hline & & & Slope & SE & Slope & SE & Slope & SE \\
\hline Crimson rosella & 43.58 & 6.50 & -0.011 & 0.023 & -0.005 & 0.019 & 0.050 & 0.020 \\
\hline Striated pardalote & 35.75 & $41.08 * * *$ & -0.133 & 0.027 & 0.078 & 0.020 & 0.019 & 0.020 \\
\hline Weebill & 34.90 & $61.84 * * *$ & -0.129 & 0.025 & 0.075 & 0.022 & 0.102 & 0.021 \\
\hline Australian magpie & 30.41 & $19.40 * * *$ & 0.046 & 0.023 & 0.006 & 0.022 & 0.084 & 0.021 \\
\hline Grey fantail & 24.04 & $41.31 * * *$ & -0.198 & 0.033 & -0.008 & 0.023 & -0.049 & 0.021 \\
\hline Galah & 23.67 & $50.21 * * *$ & 0.086 & 0.026 & 0.008 & 0.029 & 0.145 & 0.023 \\
\hline Buff-rumped thornbill & 18.90 & $21.96 * * *$ & -0.161 & 0.037 & 0.020 & 0.023 & 0.038 & 0.027 \\
\hline Noisy miner & 18.37 & $67.34^{* * *}$ & 0.264 & 0.045 & 0.158 & 0.035 & 0.157 & 0.044 \\
\hline Common starling & 15.61 & 7.67 & -0.123 & 0.050 & -0.053 & 0.044 & 0.014 & 0.027 \\
\hline Superb fairy-wren & 15.10 & $43.82 * * *$ & -0.228 & 0.035 & -0.072 & 0.059 & -0.025 & 0.024 \\
\hline Sulphur-crested cockatoo & 14.78 & $19.54 * * *$ & 0.108 & 0.031 & 0.010 & 0.027 & 0.079 & 0.030 \\
\hline Spotted pardalote & 14.68 & $13.22^{* *}$ & -0.080 & 0.034 & 0.057 & 0.023 & 0.035 & 0.028 \\
\hline Rufous whistler & 13.16 & $14.11^{* *}$ & -0.166 & 0.058 & -0.008 & 0.025 & -0.061 & 0.025 \\
\hline Red wattlebird & 11.65 & $16.31^{* * *}$ & 0.027 & 0.025 & 0.023 & 0.037 & 0.147 & 0.038 \\
\hline Pied currawong & 11.44 & $18.41 * * *$ & 0.038 & 0.025 & -0.015 & 0.049 & 0.154 & 0.039 \\
\hline Striated thornbill & 11.12 & $18.86^{* * *}$ & -0.165 & 0.064 & -0.051 & 0.027 & -0.089 & 0.030 \\
\hline Australian raven & 10.56 & $29.90 * * *$ & 0.035 & 0.033 & 0.041 & 0.038 & 0.152 & 0.029 \\
\hline White-throated treecreeper & 10.06 & $26.26^{* * *}$ & -0.251 & 0.053 & -0.051 & 0.028 & -0.020 & 0.034 \\
\hline Yellow-rumped thornbill & 9.98 & $17.59 * * *$ & -0.159 & 0.045 & 0.067 & 0.034 & 0.035 & 0.028 \\
\hline White-plumed honeyeater & 8.17 & $10.36^{*}$ & -0.326 & 0.212 & -0.165 & 0.061 & -0.023 & 0.030 \\
\hline Mistletoebird & 6.61 & $23.77 * * *$ & -0.229 & 0.062 & 0.077 & 0.036 & -0.088 & 0.038 \\
\hline Magpie-lark & 6.40 & $20.72 * * *$ & -0.042 & 0.049 & -0.005 & 0.043 & 0.188 & 0.042 \\
\hline White-throated gerygone & 6.24 & $17.53^{* * *}$ & -0.423 & 0.117 & -0.001 & 0.034 & -0.076 & 0.036 \\
\hline White-winged chough & 5.79 & $24.93^{* * *}$ & -0.080 & 0.057 & 0.101 & 0.034 & 0.196 & 0.052 \\
\hline Red-rumped parrot & 5.73 & $21.90 * * *$ & -0.545 & 0.129 & 0.329 & 0.162 & -0.005 & 0.031 \\
\hline Crested pigeon & 5.65 & $53.58 * * *$ & 0.230 & 0.047 & 0.271 & 0.068 & 0.170 & 0.046 \\
\hline Common myna & 5.39 & $68.24^{* * *}$ & -0.319 & 0.045 & 0.162 & 0.119 & 0.201 & 0.049 \\
\hline Speckled warbler & 4.64 & $26.20 * * *$ & -0.107 & 0.047 & 0.180 & 0.058 & 0.157 & 0.047 \\
\hline Willie wagtail & 3.90 & 7.30 & -0.408 & 0.156 & 0.036 & 0.055 & -0.002 & 0.038 \\
\hline White-eared honeyeater & 3.77 & $32.25^{* * *}$ & -0.049 & 0.057 & 0.126 & 0.056 & 0.263 & 0.051 \\
\hline Brown-headed honeyeater & 3.69 & $8.79 *$ & -0.268 & 0.125 & 0.074 & 0.038 & -0.030 & 0.055 \\
\hline Grey shrike-thrush & 3.40 & $8.66^{*}$ & -0.266 & 0.103 & -0.067 & 0.054 & -0.025 & 0.040 \\
\hline Tree martin & 3.37 & $28.17 * * *$ & 0.017 & 3.000 & -0.230 & 0.155 & -0.182 & 0.036 \\
\hline Silvereye & 3.24 & $20.21^{* * *}$ & -0.249 & 0.056 & 0.010 & 0.057 & -0.012 & 0.059 \\
\hline Brown thornbill & 3.13 & 6.27 & -0.162 & 0.072 & -0.049 & 0.064 & -0.032 & 0.043 \\
\hline Australian king-parrot & 2.81 & $10.29 *$ & 0.080 & 0.040 & 0.167 & 0.144 & 0.516 & 0.236 \\
\hline Golden whistler & 2.71 & $9.34^{*}$ & -0.207 & 0.069 & 0.003 & 0.053 & -0.035 & 0.057 \\
\hline Leaden flycatcher & 2.42 & $10.53^{*}$ & -0.262 & 0.089 & 0.075 & 0.056 & -0.023 & 0.069 \\
\hline Dusky woodswallow & 1.80 & 7.44 & -0.283 & 0.118 & -0.151 & 0.117 & -0.003 & 0.051 \\
\hline Grey currawong & 1.65 & 7.57 & -0.194 & 0.079 & -0.099 & 0.823 & 0.010 & 0.081 \\
\hline Sacred kingfisher & 1.04 & $12.05^{* *}$ & 0.049 & 0.163 & 0.163 & 0.077 & 0.302 & 0.110 \\
\hline
\end{tabular}


Lichenostomus leucotis (Supplementary material Appendix 1, Table A1). All increasers were represented on unreserved sites, while pre- and post-1995 reserved sites represented nine and six species respectively.

2) Decliners. Twelve species were identified as decliners in this study (Table 2). Of these, two showed significant decreasing trends across all reservation categories. These species were the striated thornbill Acanthiza lineata and superb fairy-wren Malurus cyaneus. Of the 12 decliners, 11 were defined as woodland-dependent species (Supplementary material Appendix 1, Table A1). The only decliner that was not dependent on woodland was the white-plumed honeyeater Lichenostomus pencillatus. Almost all decliners were represented on pre-1995 reserves (except the tree martin Hirundo nigricans) while post-1995 reserves and unreserved sites supported seven and six species, respectively.

3) Contrasting trends. Eleven species exhibited contrasting trends that were dependent on reservation category (Table 2). The most common pattern of contrasting trends was for a species to decline on pre-1995 reserved sites, while increasing on post-1995 reserved sites $(n=4)$ or unreserved sites $(n=1)$ or both $(n=6)$ (Table 2$)$. Such species included the striated pardalote Pardalotus striatus and speckled warbler Chthonicola sagittata (Table 2). Only one species, the mistletoebird Dicaeum hirundinaceum, showed a decreasing trend on both pre-1995 reserved sites and unreserved sites, while increasing on post-1995 reserved sites (Table 2). Seven of the species listed here are dependent on woodland (Supplementary material Appendix 1, Table A1).

\section{General trends across reservation category}

Post-1995 reserved sites and unreserved sites showed similar patterns in the number of species with increasing $(n=17$ and 19 , respectively) and decreasing $(\mathrm{n}=7$ for both) trends (Table 2). Pre-1995 reserved sites showed very different results with nine species exhibiting an increasing trend and 23 species exhibiting a decreasing trend (Table 2). Of these 23 decreasing species, 14 were unique to pre-1995 reserved sites, showing stable or increasing trends across other reservation categories (Table 2). There were no declining species unique to post-1995 reserved sites or unreserved sites. That is, neither of these reservation categories supported species with decreasing trends that did not also show a decrease in another category.

\section{Functional trait relationships}

Both the 2000 and 2010 RLQ analyses performed best with a single common set of variables (permutation test $\mathrm{p}<0.001$; Table 3). These included two environmental descriptors: woody vegetation cover within $500 \mathrm{~m}$ of sites and distance from the urban boundary, and three species functional traits: habitat specialisation, body size and whether the species feeds on the ground (Fig. 4). The first axes of the 2000 and 2010 RLQ analyses explained 80 and $87 \%$ of total variance in environmental conditions and species functional traits across reservation, respectively. Thus, results here are presented along a single axis of eigenvalues standardised for separate years.

In both the 2000 and 2010 RLQ analyses, we observed clear differences in the functional groups and environmental conditions associated with reserved versus unreserved sites (Fig. 4). Reserved sites were more strongly associated with woody vegetation cover, and large, ground-feeding bird species that were not strictly dependent on woodland habitat. Unreserved sites were typically located further from the urban boundary and more strongly associated with smaller, non-ground-feeding birds that were woodland-dependent. While differing slightly in strength, the direction of these associations remained consistent across the two time periods analysed.

\section{Environmental descriptors across reservation categories}

\section{Static differences in environmental descriptors at the reserve-level}

We found that pre-1995 reserves were significantly higher in elevation and relative topographic position than post-1995 reserves (Table 4). Compared to pre-1995 reserves, post1995 reserves were generally larger with lower levels of woody vegetation cover based on the calculated reserve means. However, these results were not statistically significant (Table 4).

\section{Static differences in environmental descriptors at the site-level}

Potential productivity was significantly higher on unreserved sites when compared to reserved sites (Table 4). This trend

Table 3. Results of RLQ analysis. Eingenvalues for the first two axes of: (a) individual ordinations of the R (environmental variables of each site), L (species detection at sites) and Q (bird species traits) matrices, and (b) RLQ analysis, including covariance and correspondence with the $\mathrm{L}$ matrix, and projected variance of the $\mathrm{R}$ and $\mathrm{Q}$ matrices. Percent variance explained by each analysis component is shown in parentheses.

\begin{tabular}{|c|c|c|c|c|}
\hline & \multicolumn{2}{|c|}{$\begin{array}{c}2000 \\
\text { Simulated p-value: }<0.001\end{array}$} & \multicolumn{2}{|c|}{$\begin{array}{c}2010 \\
\text { Simulated p-value: }<0.001\end{array}$} \\
\hline & Axis $1(\%)$ & Axis $2(\%)$ & Axis $1(\%)$ & Axis $2(\%)$ \\
\hline \multicolumn{5}{|l|}{ (a) Individual ordinations: } \\
\hline R (Hill-Smith PCA) & $1.83(60.87)$ & $0.78(25.85)$ & $1.81(60.24)$ & $0.69(23.09)$ \\
\hline $\mathrm{L}(\mathrm{CA})$ & $0.28(8.93)$ & $0.20(6.39)$ & $0.34(11.75)$ & $0.18(6.09)$ \\
\hline Q (Hill-Smith PCA) & $1.88(46.89)$ & $1.02(25.44)$ & $1.82(45.45)$ & $1.03(25.78)$ \\
\hline \multicolumn{5}{|l|}{ (b) RLQ analysis: } \\
\hline RLQ axis eigenvalues & $0.06(79.58)$ & $0.01(20.38)$ & $0.07(86.60)$ & $0.01(13.02)$ \\
\hline Covariance & 0.24 & 0.12 & 0.26 & 0.10 \\
\hline Correlation: $\mathrm{L}$ & $0.15(28.41)$ & $0.12(25.77)$ & $0.16(27.79)$ & $0.12(27.41)$ \\
\hline Projected variance: $\mathrm{R}$ & $1.42(77.59)$ & $2.55(98.14)$ & $1.63(89.96)$ & $2.36(94.27)$ \\
\hline Projected variance: $\mathrm{Q}$ & $1.77(94.14)$ & $2.72(94.17)$ & 1.55 (85.19) & $2.57(90.37)$ \\
\hline
\end{tabular}




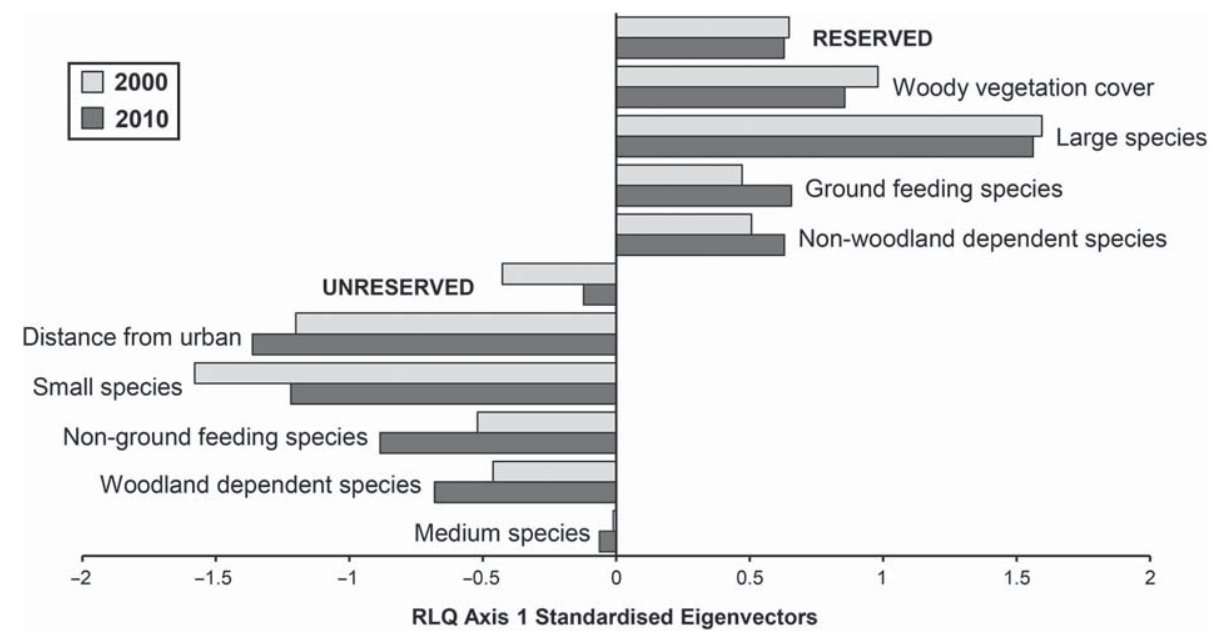

Figure 4. Standardised eigenvectors for axis 1 of RLQ analyses relating bird species occurrence on reserved and unreserved sites to environmental variables and species traits for the years 2000 and 2010. Variables with positive standardised eigenvectors are more strongly associated with reserved sites. Variables with negative standardised eigenvectors are more strongly associated with unreserved sites. Increasing difference from zero indicates increasing contribution to the variance explained by the analysis.

was reversed for measured plant productivity. Mean cover of woody vegetation at the site-level was significantly higher on reserved sites than unreserved sites. There also was a significant difference in urban proximity across reservation categories, with pre-1995 reserves situated nearest to the urban boundary, followed by post-1995 reserves, and unreserved sites situated the furthest from the urban boundary.

\section{Temporal change in environmental descriptors at the site-level}

While potential productivity (calculated from abiotic measures) increased across all reservation categories over time, measured plant productivity decreased. Cover of woody vegetation decreased consistently over time and across all reservation categories. The urban boundary encroached on all sites, but this trend was only significant and particularly strong for post1995 reserved sites (Table 4).

\section{Discussion}

Whether originally located on species-rich sites, or actively managed to prevent habitat degradation, protected areas are expected to foster positive relationships with biodiversity (Jackson et al. 2009). In this study, we assessed the ecological effectiveness of protected areas for conserving bird diversity by examining the long-term response of species to the presence and absence of protection. We posed four key questions to empirically test the long-term effect of protected areas on: 1) species richness, 2) species of

Table 4. Comparison of environmental conditions across reservation categories. Differences in the physical characteristics of reserves (pre- and post-1995 reserved sites) are expressed using means with standard errors (SE). Differences and trends in environmental conditions across reservation categories (pre- and post-1995 reserved sites and unreserved sites) are expressed using the estimate (Est.) and slope respectively, including standard errors (SE). Significance is indicated using the Wald statistic $\left(\chi_{\mathrm{df}}^{2}\right)$ and $p$-value as follows: ${ }^{*} p<0.05, * * p<0.01$, $* * * p<0.001$. Non-significant relationships are presented in grey. Details on source and method of data collection for each environmental covariate are provided in Supplementary material Appendix 2, Table A2.

\begin{tabular}{|c|c|c|c|c|c|c|c|}
\hline \multirow{2}{*}{$\begin{array}{l}\text { Environmental measure } \\
\text { Static data (reserve category) }\end{array}$} & \multirow{2}{*}{$\frac{\text { Significance }}{\mathrm{F}_{1,5}}$} & \multicolumn{2}{|c|}{$\begin{array}{l}\text { Pre-1995 } \\
\text { reserved sites }\end{array}$} & \multicolumn{2}{|c|}{$\begin{array}{l}\text { Post-1995 } \\
\text { reserved sites }\end{array}$} & \multicolumn{2}{|c|}{ Unreserved sites } \\
\hline & & Mean & SE & Mean & SE & - & - \\
\hline Reserve area (ha) & 0.93 & 378.30 & 114.40 & 546.70 & 132.10 & - & - \\
\hline Reserve elevation (m) & $7.06^{*}$ & 705.04 & 12.08 & 656.01 & 13.95 & - & - \\
\hline Reserve landscape position & $26.14^{* *}$ & -1.19 & 0.16 & 0.06 & 0.18 & - & - \\
\hline Site woody cover & 2.75 & 0.38 & 0.10 & 0.12 & 0.12 & - & - \\
\hline Pooled temporal data (reserve category) & $\chi_{3}^{2}$ & Est. & SE & Est. & SE & Est. & SE \\
\hline Potential productivity & $2226 * * *$ & 1.772 & 0.054 & 1.730 & 0.058 & 1.849 & 0.060 \\
\hline Plant productivity & $2796 * * *$ & 1.530 & 0.039 & 1.494 & 0.040 & 1.481 & 0.045 \\
\hline Woody cover (within 500 m) & $107 * * *$ & 3.525 & 0.407 & 2.852 & 0.413 & 2.386 & 0.483 \\
\hline Distance to urban boundary & $867 * * *$ & 6.679 & 0.328 & 7.022 & 0.321 & 7.759 & 0.393 \\
\hline Temporal data (reserve category $\times$ year) & $\chi_{3}^{2}$ & Slope & SE & Slope & SE & Slope & SE \\
\hline Potential productivity & $23^{* * *}$ & 0.010 & 0.005 & 0.015 & 0.004 & 0.008 & 0.004 \\
\hline Plant productivity & $244^{* * *}$ & -0.019 & 0.002 & -0.020 & 0.002 & -0.012 & 0.002 \\
\hline Woody cover (within 500 m) & $176 * * *$ & -0.059 & 0.008 & -0.091 & 0.009 & -0.060 & 0.014 \\
\hline Distance to urban boundary & $418 * * *$ & -0.009 & 0.012 & -0.087 & 0.004 & -0.007 & 0.004 \\
\hline
\end{tabular}


conservation concern, 3) species persistence and 4) species functional groups.

We found that, compared to unprotected areas, protected areas collectively supported: 1) lower species richness, 2) fewer species of conservation concern, 3) more species with declining trends, and 4) larger-bodied, generalist species. By these measures, we can conclude that unprotected areas sampled in this study are more effective in maintaining woodland bird diversity than protected areas within our study region. This is a striking and counter-intuitive result which we explore within the physical and ecological context of protected areas below. Specifically, we draw attention to three key findings.

1) Reserve placement influenced ecological effectiveness over time. Our results indicated that the long-term response of birds to protected areas was strongly influenced by the period of protected-area establishment. Long-established protected areas may be limited in their capacity to meet conservation objectives due to reserve design that was not ecologically-driven. For example, creating reserves to protect scenic values (Margules and Pressey 2000) and establishing reserves on less productive land (Joppa and Pfaff 2009). Indeed, we found that reserves established before 1995 in this study were significantly higher in elevation, higher in topographic position, had lower potential productivity and, on average, were smaller in size than post1995 reserves (although this last finding was not statistically significant).

In 1994, an amendment to the Nature Conservation Act 1980 in the ACT (ACT 1994) introduced a statutory requirement to conserve endangered ecological communities. Since that time, the characteristics of newer reserves have changed (Table 4) and our analyses indicated that their ecological effectiveness has improved. This was exemplified by increasing species richness, stabilisation of species populations of conservation concern and fewer individual species declines, particularly of less common specialist species, on post-1995 reserves when compared to pre-1995 reserves. Hence, this study demonstrated that overcoming traditional biases in reserve placement and re-prioritising designation objectives can enhance the ecological effectiveness of protected areas.

2) Reserves protect habitat and ecological processes. Despite an overall decline in woody vegetation cover across study sites (Table 4), our reserved sites supported significantly higher vegetative cover and productivity than unreserved sites (Fig. 3, Table 4). Other studies have found protected areas to be effective in representing and maintaining vegetation cover (Andam et al. 2008) and plant productivity (Tang et al. 2011). Such outcomes demonstrate that, where enforcement is adequate, protected areas can play a critical role in preserving habitat and maintaining ecological processes through legislative controls of destructive processes, such as land clearing, and can therefore be associated with enhanced protected-area performance (Stoll-Kleemann and Job 2008).

However, this may not strictly be the case for all woodland birds. For example, some argue that vegetation thickening favours the more specialised woodland bird species (Kutt and Martin 2010), but Montague-Drake et al. (2011) found that overstorey cover and productivity were positively related to the abundance of hyper-aggressor Manorina melanocephala; a species linked to declines in avian diversity and abundance (MacDonald and Kirkpatrick 2003). In our study, Manorina melanocephala exhibited highest detection and strongest increasing trends within reserves (Supplementary material Appendix 4, Table A4) and could be driving localised species declines. This example demonstrates that while the maintenance of vegetation characteristics within protected areas may provide broader landscape functions for biota (e.g. connectivity), additional on-site management actions (e.g. population control of interspecific competitors) may be required to secure vulnerable species populations.

3) Urban encroachment threatens ecological effectiveness. In this study, smaller woodland-dependent species were associated with unprotected sites situated furthest from urban boundaries (Fig. 4, Table 4). While studies have shown positive relationships between human population density and avian richness (due to a mutually positive response to primary productivity, Luck 2010), such relationships are highly scale-dependent, with more localised effects tending to be negative (Pautasso 2007). Indeed, the direct effects of urban encroachment on protected areas and their associated biodiversity are often negative (Radeloff et al. 2010). The mechanisms which underpin the negative relationship between small, woodland-dependent species and urban proximity identified in this study are unclear, but may be associated with habitat or species composition changes within reserves close to the urban fringe (Ikin et al. 2012). This is of particular concern as urban encroachment is advancing rapidly toward the best-performing reserves in our study region (Table 4). Here, buffering protected areas from the impacts of urban development will become increasingly important as urban areas expand and opportunities for establishing future reserve sites contract (Ewers and Rodrigues 2008).

Together, our findings demonstrate that protected areas are dynamic systems, exhibiting their own temporal and spatial response to environmental gradients. We have shown that the conservation performance of protected areas can diminish over time with changes in landscape context. It is also likely that protected area effectiveness will be influenced by increasing environmental pressures associated with climate change (Hole et al. 2011, Araujo et al. 2011, Bagchi et al. 2013). For example, survey data for this study were collected during a period of severe drought in Australia (2001-2009) and one could suggest that reserve performance may improve during years of higher rainfall. However, projected climate changes include increased frequency and severity of drought for our study region, indicating that the results presented here may provide a good indication of future trends. Further research is needed to quantify the effect of weather on bird distributions in this region, and to determine whether protected areas are likely to facilitate (Thomas et al. 2012) or inhibit (Araujo et al. 2011) species' range expansions.

Given that protected area performance may fluctuate through space and time, studies of ecological effectiveness that incorporate comparative and temporal data are better equipped to track changes in protected systems relative to un-protected systems, identify the processes threatening protected-area 
performance, and assess the success (or otherwise) of management interventions addressing those processes.

Our results illustrate how studies that lack comparative data fail to examine the direct effect of protection on biodiversity and, therefore, are limited in their assessments of species representativeness. Similarly, studies that lack temporal data fail to examine the sustained effect of protection on biodiversity and therefore, will be limited in their assessments of species persistence. Importantly, these two measures, representativeness and persistence, are widely recognised as primary indicators of protected-area performance (Margules and Pressey 2000) and should be addressed wherever possible in assessments of ecological effectiveness.

\section{Conservation implications}

Our study joins a substantial body of work acknowledging the benefits and importance of protected areas, while also identifying significant shortfalls in their conservation performance (Vellak et al. 2009, Fandohan et al. 2011). We believe our study has taken a first step in addressing these shortfalls by quantifying the outcomes of past conservation efforts and establishing a contemporary ecological context to inform future systematic planning (sensu Hockings et al. 2004). The similar, and sometimes superior, performance of unprotected areas in comparison to protected areas was unexpected, but not unique to this study region (e.g. China, Liu et al. 2001; Canada, Kharouba and Kerr 2010; Europe, Araujo et al. 2011). Such findings suggest that the protection of modified habitats situated more favourably in the landscape (in terms of surrounding land-use threats and changing climate space) could maximise conservation benefits to a region, particularly where active restoration is feasible. Perhaps more importantly, it highlights that options for conservation are not limited to protected areas, and that there is great potential for biodiversity gains through investments in off-reserve conservation schemes (Lindenmayer and Franklin 2002, Cox and Underwood 2011).

The protected-area portfolio in the ACT has $99 \%$ of all ecosystems represented to the minimum global conservation target of $10 \%$ (Taylor et al. 2011). But does this mean that it is ecologically effective for conserving biodiversity? Our study showed that the protection of ecosystems has been effective in the maintenance of some ecological patterns and processes (i.e. vegetative cover and productivity), but has not been effective in ensuring the persistence of a vulnerable assemblage of species (i.e. woodland birds). Thus, a key lesson from this study is that the use of performance measures that are not necessarily proxies for ecological effectiveness (e.g. habitat classes, Brooks et al. 2004; or areal coverage, Gaston et al. 2008) can severely limit our capacity to understand and describe the actual performance of protected areas for biodiversity, particularly at the resolution needed for the on-ground adaptive management of species populations. This is not to say that direct biodiversity data should replace generalised environmental variables in evaluations of protected area effectiveness. Indeed, monitoring a potentially unrepresentative assemblage of species will not, in itself, provide a comprehensive assessment of performance. Rather, we argue that species-specific data are needed to complement broader environmental data and that, where biodiversity data are lacking, assumptions of species persistence within protected areas should be made with great caution until such data are gathered.

Acknowledgements - This research received funding support from Conservation Planning and Research, Environment and Sustainable Development Directorate ACT Government and the Fenner School of Environment and Society. We thank the Canberra Ornithologists Group (COG) for providing bird records, J. Kesteven and the National Carbon Accounting Service (NCAS) for calculating fpi data, and B. Mackey and colleagues for calculating PPAR data. We also thank K. Ikin, C. Sato for improvements to the manuscript; and M. Evans and J. Stein for valuable contributions.

\section{References}

[ACT] Australian Capital Territory Government 1994. Australian Capital Territory Legislative Assembly: Nature Conservation (Amendment) Bill 1994, Explanatory Memorandum. - <www.legislation.act.gov.au/es/db_14972/ 19940616-16965/pdf/db_14972.pdf> accessed 7 May 2013.

[ACT] Australian Capital Territory Government 2004. Woodlands for Wildlife: ACT Lowland Woodland Conservation Strategy. Action Plan No. 27. - < www.environment.act.gov.au/data/ assets/pdf_file/0010/234487/actionplan27t1.pdf > accessed 21 February 2013.

[ACT] Australian Capital Territory Government 2011. ACT State of the Environment Report 2011. - < www.envcomm.act.gov. au/actsoe2011/index.html $>$ accessed 21 February 2013.

[ACTFFC] Australian Capital Territory Flora and Fauna Committee 2011. Thirteenth Annual Report: 2010-2011. - <www. environment.act.gov.au/cpr/conservation_and_ecological_ communities/act_flora_and_fauna_committee $>$ accessed 21 February 2013.

Andam, K. S. et al. 2008. Measuring the effectiveness of protected area networks in reducing deforestation. - Proc. Natl Acad. Sci. USA 105: 16089-16094.

Araujo, M. B. et al. 2011. Climate change threatens European conservation areas. - Ecol. Lett. 14: 484-492.

Bagchi, R. et al. 2013. Evaluating the effectiveness of conservation site networks under climate change: accounting for uncertainty. - Global Change Biol. 19: 1236-1248.

Bertzky, B. et al. 2012. Protected Planet Report 2012: tracking progress towards global targets for protected areas. - IUCN, Gland, Switzerland and UNEP-WCMC, Cambridge, UK.

Bounds, J. et al. 2010. A statistical analysis of trends in occupancy rates of woodland birds in the ACT, December 1998 to December 2008: the ten-year data analysis. - Canberra Bird Notes 35: 158-192.

Brooks, T. M. et al. 2004. Protected areas and species. - Conserv. Biol. 18: 616-618.

Chace, J. F. and Walsh, J. J. 2006. Urban effects on native avifauna: a review. - Landscape Urban Plann. 74: 46-69.

Cox, R. L. and Underwood, E. C. 2011. The importance of conserving biodiversity outside of protected areas in Mediterranean ecosystems. - PLoS One 6: e14508.

DeFries, R. et al. 2005. Increasing isolation of protected areas in tropical forests over the past twenty years. - Ecol. Appl. 15: $19-26$

Devictor, V. and Robert, A. 2009. Measuring community responses to large-scale disturbance in conservation biogeography. - Divers. Distrib. 15: 122-130.

Doledec, S. et al. 1996. Matching species traits to environmental variables: a new three-table ordination method. - Environ. Ecol. Stat. 3: 143-66. 
Dudley, N. 2008. Guidelines for applying protected area management categories. - IUCN, Gland, Switzerland.

Ervin, J. 2003. Protected area assessments in perspective. - Bioscience 53: 819-822.

Ewers, R. M. and Rodrigues, A. S. L. 2008. Estimates of reserve effectiveness are confounded by leakage. - Trends Ecol. Evol. 23: 113-116.

Fandohan, B. et al. 2011. Effectiveness of a protected areas network in the conservation of Tamarindus indica (LeguminoseaCaesalpinioideae) in Benin. - Afr. J. Ecol. 49: 40-50.

[FAO] Food and Agriculture Organization of the United Nations 2011. State of the world's forests 2011. - < www.fao.org/docrep/ 013/i2000e/i2000e00.htm > accessed 21 February 2013.

Filippi-Codaccioni, O. et al. 2010. Toward more concern for specialisation and less for species diversity in conserving farmland biodiversity. - Biol. Conserv. 143: 1493-1500.

Gaston, K. J. et al. 2006. The ecological effectiveness of protected areas: The United Kingdom. - Biol. Conserv. 132: 76-87.

Gaston, K. J. et al. 2008. The ecological performance of protected areas. - Annu. Rev. Ecol. Evol. Syst. 39: 93-113.

Hockings, M. et al. 2004. Management effectiveness: assessing management of protected areas? - J. Environ. Pol. Plann. 6: $157-174$

Hoekstra, J. M. et al. 2005. Confronting a biome crisis: global disparities of habitat loss and protection. - Ecol. Lett. 8: 23-29.

Hole, D. G. et al. 2011. Toward a management framework for networks of protected areas in the face of climate change. Conserv. Biol. 25: 305-315.

Huth, N. and Possingham, H. P. 2011. Basic ecological theory can inform habitat restoration for woodland birds. - J. Appl. Ecol. 48: 293-300.

Ikin, K. et al. 2012. The influence of native versus exotic streetscape vegetation on the spatial distribution of birds in suburbs and reserves. - Divers. Distrib. 19: 294-306.

Jackson, S. F. et al. 2009. Statutory protected areas and avian species richness in Britain. - Biodivers. Conserv. 18: 2143-2151.

Jenkins, C. N. and Joppa, L. 2009. Expansion of the global terrestrial protected area system. - Biol. Conserv. 142: 2166-2174.

Jones, J. P. G. et al. 2011. The why, what, and how of global biodiversity indicators beyond the 2010 target. - Conserv. Biol. 25: 450-457.

Joppa, L. N. and Pfaff, A. 2009. High and far: biases in the location of protected areas. - PLoS One 4: e8273.

Joppa, L. N. et al. 2008. On the protection of "protected areas". - Proc. Natl Acad. Sci. USA 105: 6673-6678.

Kharouba, H. M. and Kerr, J. T. 2010. Just passing through: global change and the conservation of biodiversity in protected areas. - Biol. Conserv. 143: 1094-1101.

Kutt, A. S. and Martin, T. G. 2010. Bird foraging height predicts bird species response to woody vegetation change. - Biodivers. Conserv. 19: 2247-2262.

Lee, Y. et al. 2006. Generalized linear models with random effects: unified analysis via H-likelihood. - Chapman and Hall/CRC.

Lindenmayer, D. B. and Franklin, J. 2002. Conserving forest biodiversity. - Island Press.

Supplementary material (Appendix ECOG-00388 at $<$ www.oikosoffice.lu.se/appendix $>$ ). Appendix 1-4.
Lindenmayer, D. B. and Likens, G. E. 2010. The science and application of ecological monitoring. - Biol. Conserv. 143: $1317-1328$.

Liu, J. G. et al. 2001. Ecological degradation in protected areas: the case of Wolong Nature Reserve for giant pandas. - Science 292: $98-101$

Luck, G. W. 2010. Why is species richness often higher in more densely populated regions? - Anim. Conserv. 13: 442-443.

MacDonald, M. A. and Kirkpatrick, J. B. 2003. Explaining bird species composition and richness in eucalypt-dominated remnants in subhumid Tasmania. - J. Biogeogr. 30: 1415-1426.

Margules, C. R. and Pressey, R. L. 2000. Systematic conservation planning. - Nature 405: 243-253.

Mas, J. F. 2005. Assessing protected area effectiveness using surrounding (buffer) areas environmentally similar to the target area. - Environ. Monit. Assess. 105: 69-80.

Montague-Drake, R. M. et al. 2011. A reverse keystone species affects the landscape distribution of woodland avifauna: a case study using the noisy miner (Manorina melanocephala) and other Australian birds. - Landscape Ecol. 26: $1383-1394$.

[NLWRA] National Land and Water Resources Audit 2001. Australian Native Vegetation Assessment 2001. - Canberra.

Pautasso, M. 2007. Scale dependence of the correlation between human population presence and vertebrate and plant species richness. - Ecol. Lett. 10: 16-24.

Pimm, S. L. et al. 2001. Environment - can we defy nature's end? - Science 293: 2207-2208.

Radeloff, V. C. et al. 2010. Housing growth in and near United States protected areas limits their conservation value. - Proc. Natl Acad. Sci. USA 107: 940-945.

Stoll-Kleemann, S. and Job, H. 2008. The relevance of effective protected areas for biodiversity conservation: an introduction. - Gaia-Ecol. Perspect. Sci. Soc. 17: 86-89.

Tang, Z. Y. et al. 2011. Effectiveness of protected areas in maintaining plant production. - PLoS One 6: e19116.

Taylor, M. F. J. et al. 2011. Building Nature's Safety Net 2011: the state of protected areas for Australia's ecosystems and wildlife. - < http://awsassets.wwf.org.au/downloads/bi037 building_natures_safety_net_2011_6jul11.pdf $>$ accessed 21 February 2013

Thomas, C. D. et al. 2012. Protected areas facilitate species' range expansions. - Proc. Natl Acad. Sci. USA 109: $14063-14068$.

Vellak, A. et al. 2009. Past and present effectiveness of protected areas for conservation of naturally and anthropogenically rare plant species. - Conserv. Biol. 23: 750-757.

[WDPA] World Database on Protected Areas 2012. - <www. unep-wcmc.org/world-database-on-protected-areas-wdpa_76. html $>$ accessed 7 May 2013.

[WWF] World Wide Fund for Nature 2012. Living Planet Report 2012: biodiversity, biocapacity and better choices. - Gland, Switzerland, < http://awsassets.panda.org/downloads/1_lpr_ 2012_online_full_size_single_pages_final_120516.pdf > accessed 21 February 2013. 